\title{
Minor Marks and Modifications: Foot Traffic
}

You see things when you're out on the street. When you're out walking around. Not the neat gardens of the suburbs or the relentless grey of the city's centre but those other places in-between. Really in-between: going to work or going to the laundromat. Coming from school. And waiting. Lots of waiting. There are things you see when this happens. You're attuned differently to the world when you're waiting. Even when you're studiously avoiding the gaze of some potential volatility. This ecology of looking, if you'll permit the metaphor, requires both a dwelling in and a passing through. My friend Yoke Sum once picked up the term En Passant ${ }^{1}$ to describe her states of being as a traveller, in observation and critique; her body in motion through relational states. En passant: In passing, not quite dwelling but still that bodily presence and, as always, a sensory being attuned to the world.

If you ever walked down the street and wondered what a marking meant, I'll tell you: It means somebody is telling you a story about who they are, and what they are prepared to do to make you aware of it. Every time a name is written, a story gets told. It is a short story; "I was here". Depending on who is telling it and where they are telling it will determine how the story ends. Some stories will be adventures, some tragedies, and some courtroom depositions. But every single one has a star, a stage and an audience. That's all a growing youth needs to have fun. (Powers 3)

My project is not about graffiti. Not really. Or at least not in the way that writing about graffiti is usually about graffiti. This paper struggles against a hegemonic discourse in order to focus on an unrelenting blind spot in the literature. Actually, it is a number of blind spots that smudge out and overwrite a mess of acts and actors. The story goes something like this: graffiti or street art, wall writing, stencil art, wheat paste, etc. is an oppositional practice governed by the question of legitimacy. Walls are owned by someone or the state or the city. Marking them up is an affront to the rights of the person who owns that brick or spread of concrete. Marking something that is not yours is wrong. And then you flip that over and you have an oppositional practice. A territorial claim. In a nutshell. In the challenge to capitalism and neoliberal ethical regimes that govern everyday life, it is only the wealthy and powerful who have access to the attention of the masses. They have the power to circulate their ideologically rich messages. Billboards that line highways and endless televisual advertisements are evidence of this. Graffiti artists protest the sanitization and hegemonic claim on space in urban environments. But this is not all that is going on and once we shift out of an obsessive focus on this relational positioning and repositioning the blind spot is left behind and

\footnotetext{
1 Yoke Sum Wong, En Passant (written in 2004/5).
} 
something else comes into view. This provides depth to understanding the surface phenomenon of public marking in built environments.
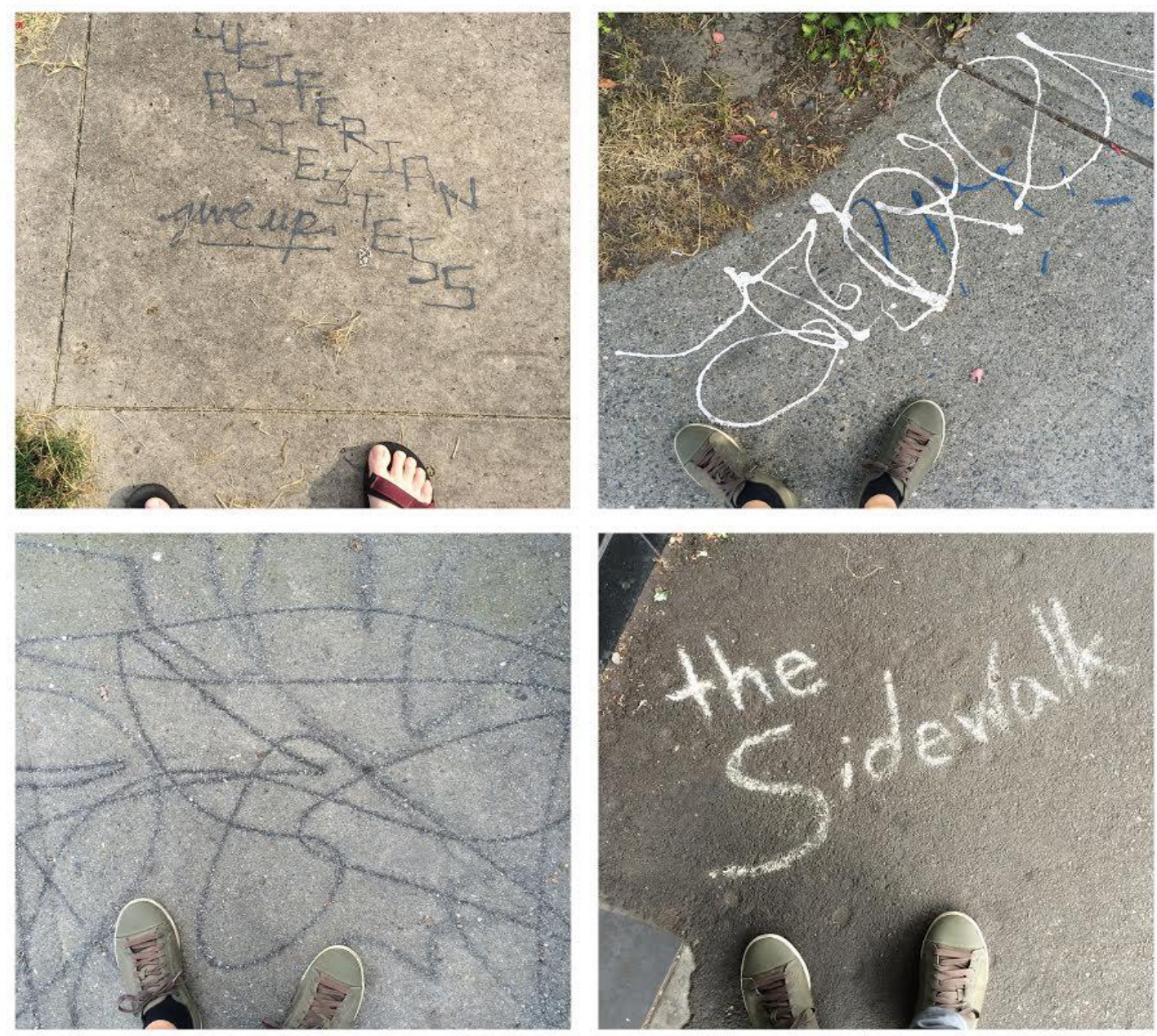

The built environments most of us now live in present a seemingly endless array of surfaces that come into and fall out of view as we move through the world. The play of revelation and obfuscation is a mundane effect produced countless times in our day to day lives. The alleys and building walls in a city produce a constant play of change and difference as we trace paths along our routes. William Burroughs characterized this effect as a surrealist montage suppressed by the banal habits of looking:

Take a walk down a city street and put down what you have just seen on canvas. You have seen a person cut in two by a car, bits and pieces of street signs and advertisements, reflections from shop windows - a montage of fragments. Writing is still confined to the representational straitjacket of the novel ... consciousness is a cut up. Every time you walk 
down the street or look out of the window, your stream of consciousness is cut by random factors. (Burroughs 61) ${ }^{2}$

Parallax comes from the Greek term for 'alteration'. We know it in English primarily as an effect of binocular vision whereby the difference in the viewing point of two eyeballs produces depth perception. The eyeballs straining through the weather on city streets are processing light and shadow, difference and repetition. They are producing information according to this queer mix of things known, things thought, and things perceived. As Slavoj Žižek argues in the Parallax View: "the subject's gaze is always-already inscribed into the perceived object itself, in the guise of its 'blind spot,' that which is 'in the object more than object itself the point from which the object itself returns the gaze. Sure the picture is in my eye, but I am also in the picture" (Žižek 17). The I that I'm after here is the eye of the pedestrian looking out at the traces of 'scene' she may or may not recognize but which are shadowing a shimmering symbolic set of meanings haunted by a real that is never quite accessible.

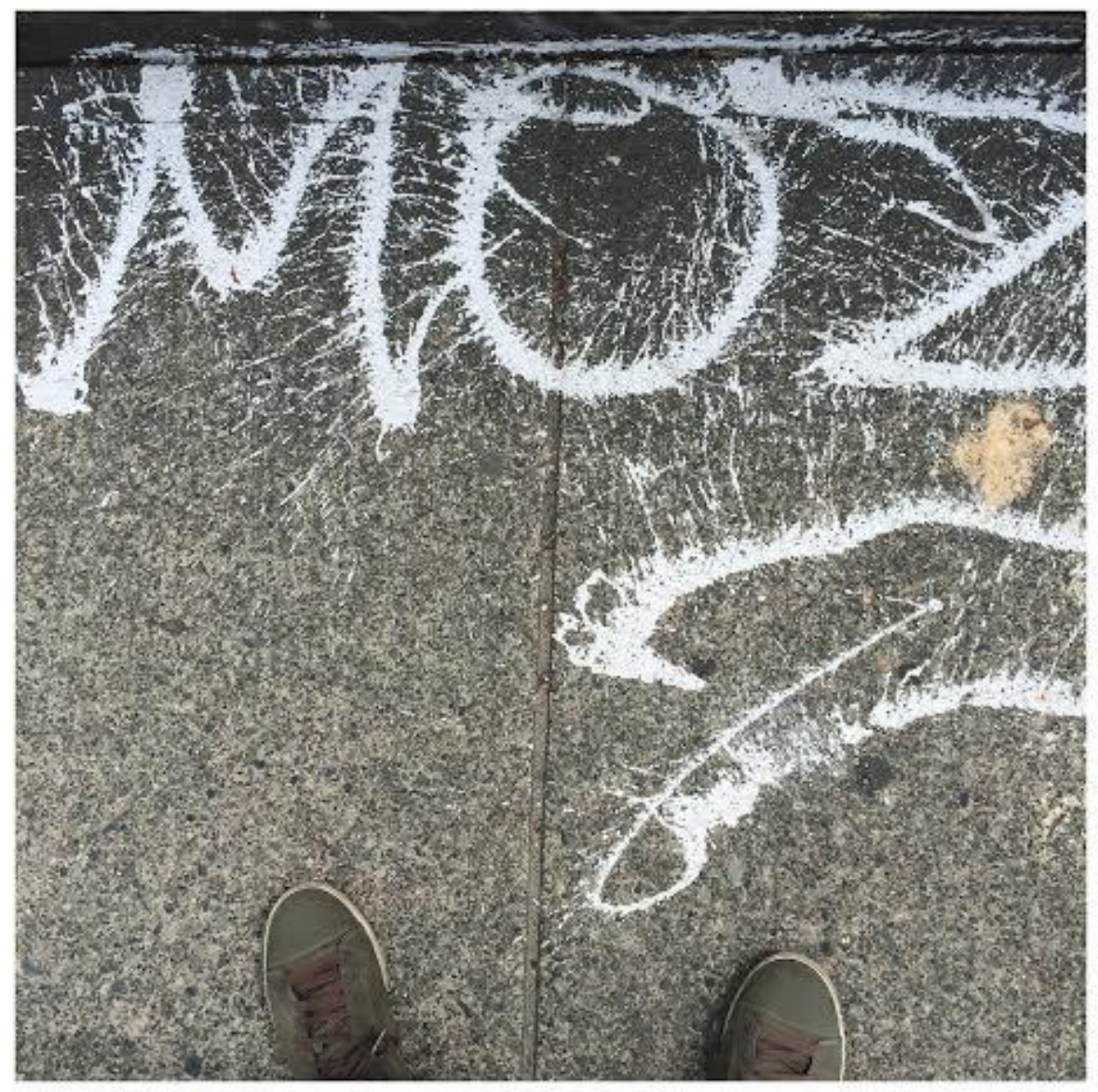

2 While Burroughs has popularized the cut-up, the Romanian DADA poet/artist Tristan Tzara is typically credited with pioneering the technique in the $1920 \mathrm{~s}$. 
TranscUlturAl, vol. 6.1 (2014), 16-27.

http://ejournals.library.ualberta.ca/index.php/TC

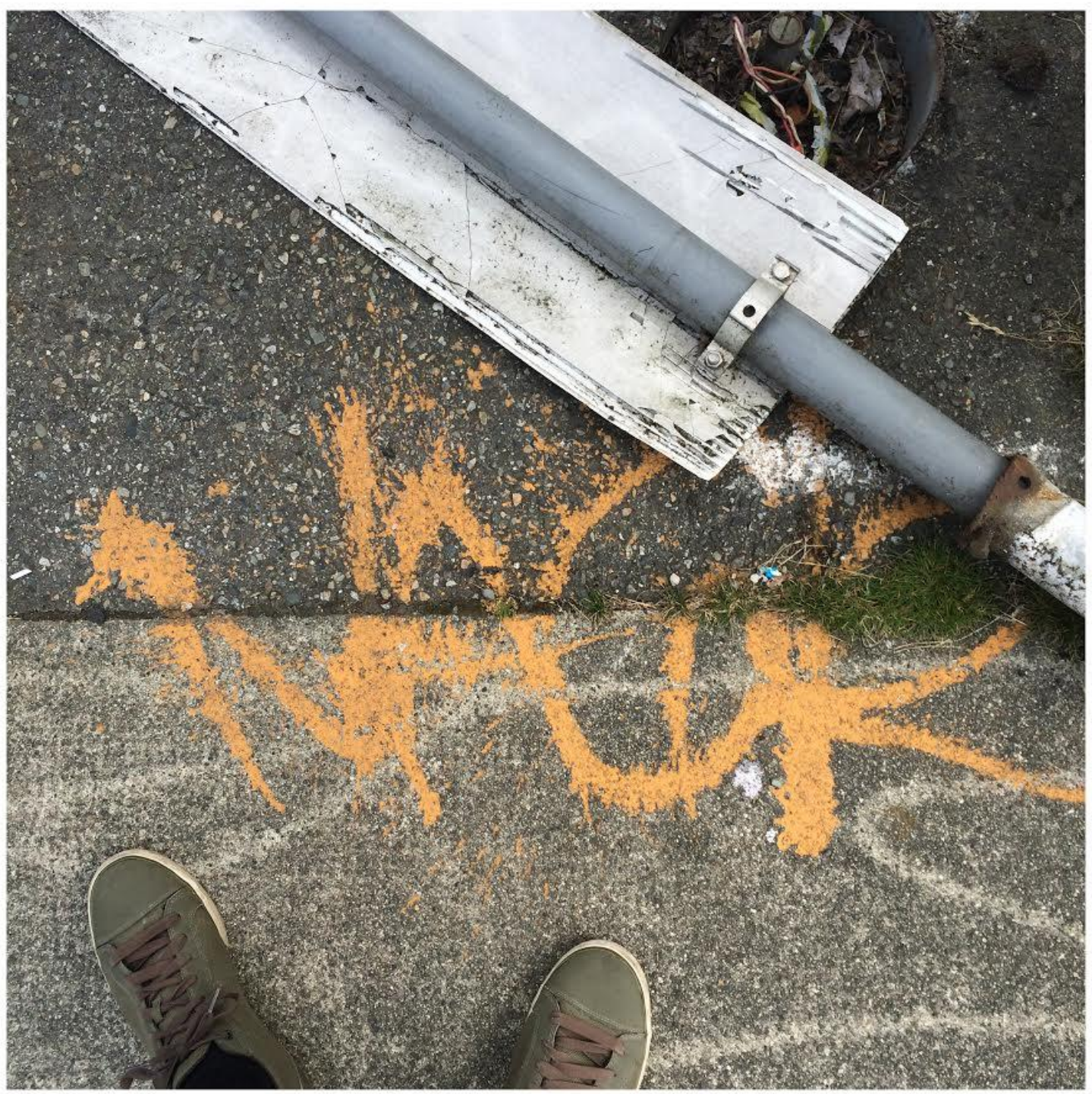

Here's de Certeau, suddenly up on the $110^{\text {th }}$ floor of the World Trade Center. ${ }^{3}$ He looks out and writes:

Seeing Manhattan from the 110th floor of the World Trade Center. Beneath the haze stirred up by the winds, the urban island, a sea in the middle of the sea, lifts up the skyscrapers over Wall Street, sinks down at Greenwich, then rises again to the crests of Midtown, quietly passes over Central Park and finally undulates off into the distance beyond Harlem. A wave of verticals. Its agitation is momentarily arrested by vision. The giant mass is immobilized

${ }^{3}$ He stopped being here in 1986. The World Trade Center in 2001. 
before the eyes. It is transformed into a texturology in which extremes coincide-extremes of ambition and degradation, brutal oppositions of races and styles, contrasts between yesterday's buildings, already transformed into trash cans, and today's urban irruptions that block out its space ... To what erotics of knowledge does the ecstasy of reading such a cosmos belong? Having taken a voluptuous pleasure in it, I wonder what is the source of this pleasure of "seeing the whole," of looking down on, totalizing the most immoderate of human texts. (Michel de Certeau 90-91)

Pedestrians represent a generic category that engulfs multiple interpretive communities. While there can be no single pedestrian gaze, there are significant differences in the observational force and engagement of the pedestrian, the cyclist, and the motorist. A kind of public exists around practices of looking at and engaging with the built urban environment from the position of a pedestrian spectator. Embodied regimes of looking can be attentive to a variety of practices of walking and inclusive of multiple communities more conventionally defined by gender, ethnicity, race, class, age, etc. The concept of spectatorship is pushed to its limits by exploring the creativity of walking and looking as more than superficial activities, mapped out on top of a built landscape. Through an examination of minor marks and modifications to the major works of street art, memorial, and urban architecture, my study of a rapidly gentrifying neighborhood in Austin, Texas, seeks to animate and trouble the zone between the supposedly passive act of looking and the more active act of transforming. Minor marks and modifications are essentially invisible to the automobile publics who consume a flattened urban landscape. Through this framework I look at the vernacular, casual, and outsider acts of pedestrian cultures; publics that are composed primarily of people who walk and spend time on the street.

In Baudrillard's System of Objects he writes: "Our urban civilization is witness to an everaccelerating procession of generations of products, appliances and gadgets by comparison with which mankind appears to be a remarkably stable species. This pullulation of objects is no odder, when we come to think about it, than that to be observed in countless natural species" (Baudrillard 1). My project doesn't mean to inventory the procession of everyday marks, but rather to explore the gaze that brings minor marks into focus and the blind-spots that keep them hidden. The pullulation or bloom of marks is a spectacle of expression consumed especially by walkers. It is part of the mass ornament that is thickly assembled as everyday's ephemeral visions.

Minor marks seem to constitute a fractured representation but taken on the whole they constitute a visual field of layered voice and history. This visual field is invisible to myriad scopic regimes: starting off with de Certeau's New York from the $110^{\text {th }}$ floor of the World Trade Center-a view that is no longer possible. But it is a view that was never possible anyway if we are to believe that looking is a situated practice. De Certeau's vantage is not unlike the view from the car. Where the tower's height obliterates detail the car's speed reduces ornament. 
Srini Kumar's multi-volume Sticker Nation is a book published as an oppositional and political statement. It is a kind of manifesto that looks to stickers for the quick and easy dissemination of national discontent: "Social groups coalesce out of inertia. But stickers sort of bridge the gap. They create 'oblique affinity groups.' . . Close your eyes and envision the completion of the grand architecture you know simply MUST be made a reality. What the world needs now is a crew of people like you-people empowered to make the visions you see happen." (Kumar 2009b: 4). Kumar's books are ugly and poorly designed but they anticipate new audiences of perennial social disaffection. These books help to direct attention to Kumar's useful category of 'oblique affinity groups.' In many ways his project helps to name a nebulous public. McGill professor Will Straw has written convincingly about 'scenes' over subcultures and notes 'the term's efficiency as a default label for cultural unities whose precise boundaries are invisible and elastic. 'Scene' is usefully flexible and anti-essentializing, requiring of those who use it no more than that they observe a hazy coherence between sets of practices or affinities" (Straw 248). Scenes and oblique affinity groups present a sociological or ethnographic object, a bounded community. The community we're interested in here, though is a community of spectators, not producers.

Scene is also a powerful way of insisting on location and spectatorship. The slippage between talking about the 'punk scene,' or the 'skater scene,' and the 'urban scene' is a useful agitational agent. This slippage can be used to gesture towards more specific spectatorial positions. But also affective sensorial ecologies that insist upon the circulation of people [rather than 'bodies']. The play of course between seen (as a verb) and scene (as a noun) is helpful. The visibility of the traces archived on concrete produces a multitude of scenes.

The people making the marks are graffiti artists, kids, non-conformists, discontents, activists, and myriad others unidentifiable in the throng of any city. They form a haphazard 'scene'. They look and watch too. So do the police and the librarians, kids, homeless people, sex workers, drifters as well as professors and students, tortilla factory workers or bar tenders and entrepreneurs; all of whom also populate the East Side of Austin. In a recent issue dedicated to a kind of retrospective of street art, editors of the popular magazine Juxtapoz note that:

Graffiti and street art had always relied on an audience in a distinct public space and locale. Pieces done in Brooklyn, Los Angeles, the Bronx, or Berlin were done so people would see, discuss, digest, understand, and interact. Where discourse and interaction with art existed solely in galleries and museums in the mid-twentieth century, this new distribution point was created in the streets throughout the 1970s, '80s, and most of the '90s. Today, the Internet has broken all barriers and rules. Work is now being created for the first point of interaction to occur on your laptop, not a physical space. The audience is infinite (or six billion people infinite). You aren't just putting a piece up in Valencia, Spain; you are sharing a piece for the world to see via their computers, smartphones, and iPads. (Revelli 8) 

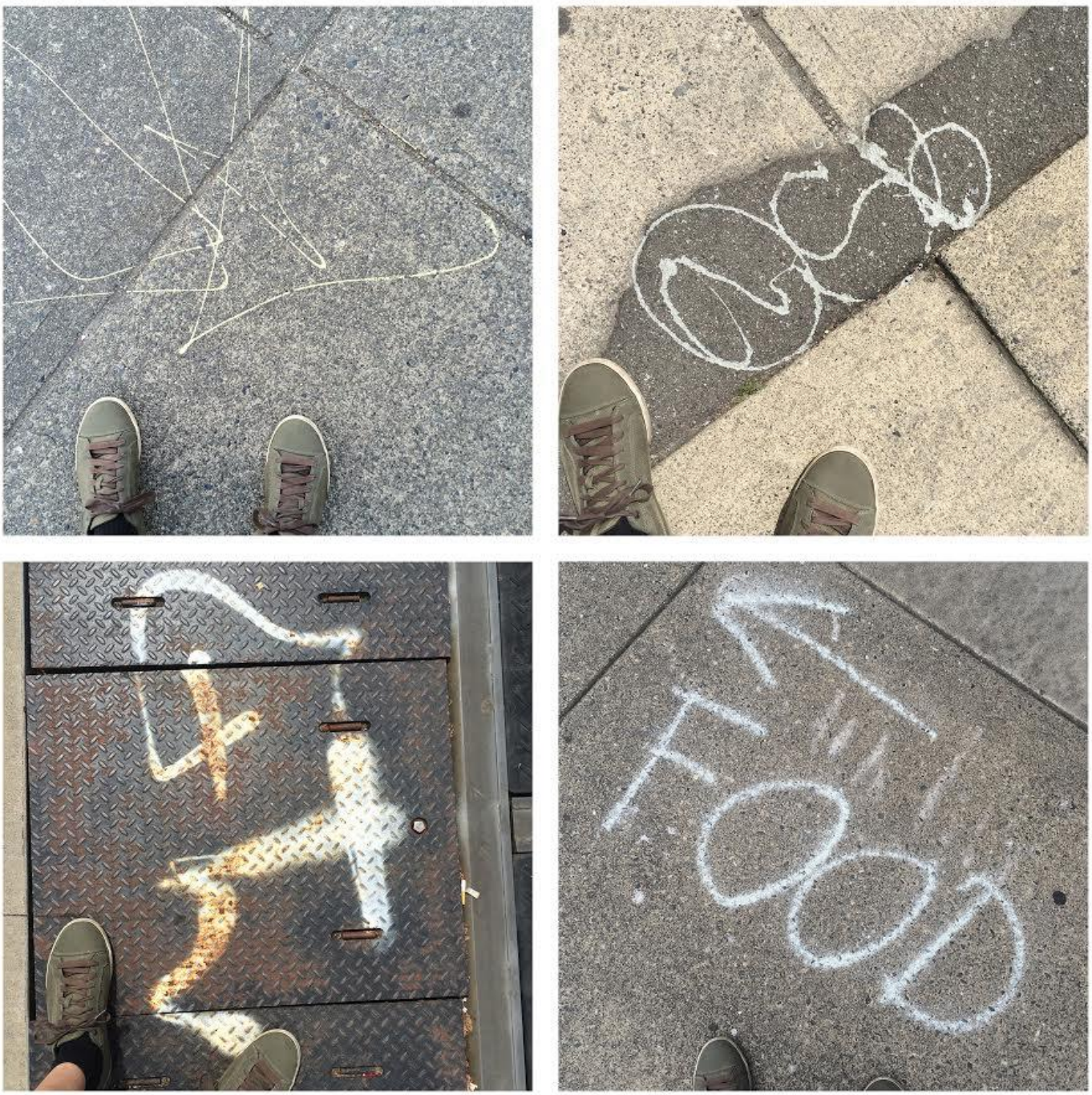

What does this approach to 'scenes' do to the 'whole culture' approach of traditional anthropology which posits that visual culture is understood as "the shared practices of a group, community, or society, through which meaning is made out of the visual, aural, and textual world of representations" (Sturken and Cartwright 3)? The kind of 'scenes' I'm talking about don't have an orthodoxy or even an easy boundary. Certainly they produce rules, refer to forms, and generate new scenes, but they are predicated on fractured communities and discontinuous groups, nonsynchronous publics. Minor marks and modifications present as a range of observable phenomena that don't fit cleanly into any recognizable system of public art. Indeed their very public - such as it is-is a precarious category. The precarity of this category is at the very heart of my interest in the phenomenon of the visual ecology of street art. 
In his article, "More to see than a canvas in a white cube: For an art in the streets," Joe Austin summarizes the anti-Graffiti programs of the 1980s:

Notions of urban visual order, usually less noticeable, were overtly mobilized within 'antigraffiti' legislation, policing practices and litigation against offenders. Presumed categories of analysis and action (e.g. 'normal' ideas of vandalism, defacement, 'cleanliness', visual order) are implied in the established strategies of municipal agencies and in city regulations regarding private property ownership, as well as in some popular film and other forms of mass culture that attempt to re-present (neo-) New York City. Here was a nostalgic dream of a formerly 'clean modernity' that had (thankfully) never existed, a unified aesthetic design for a unified social ordering that was never fully able to take place. (Austin 44)
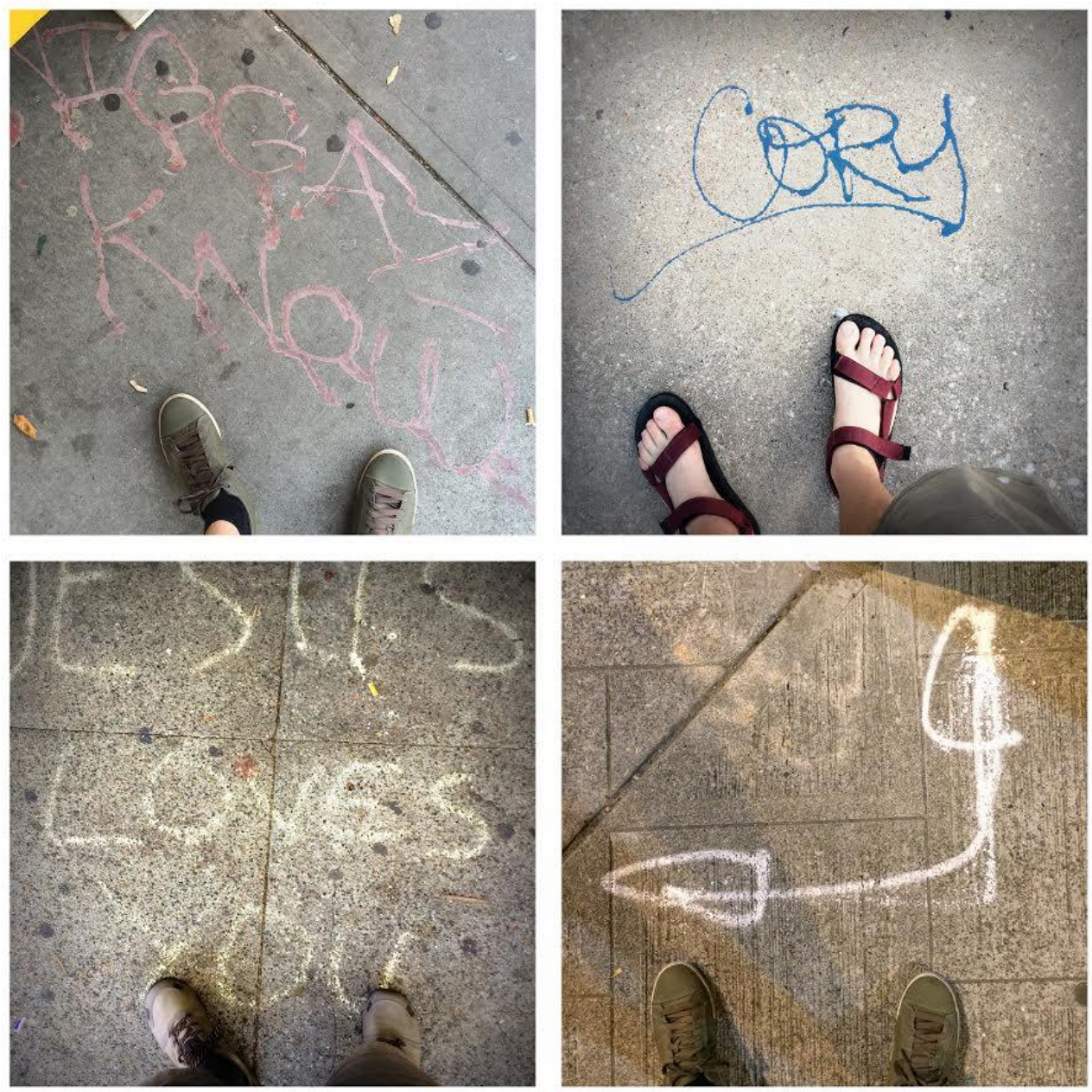

Public discourses help not only to produce categories of interpretation and hegemonies of legitimation but they produce (and re-produce) coherencies in public regimes of looking. Struggles over the legality/illegality, heroic/non-heroic status of street-art is produced not only through these 
official and popular discourses but through everyday encounters with the built environment. Of course, even when we might want to side-step the politics of graffiti, another kind of politics emerge as a definitional form.

The sociologist Eric Gordon explores Sigfried Kracauer's notion of the "mass ornament" in his book The Urban Spectator. He argues, along with Kracauer, that the mass ornament is a useful frame for understanding and assessing a historical period. It is the "inconspicuous surface-level expressions" (Kracauer in Gordon 61) experienced as part of everyday life that are the most revelatory. This mass ornament I'm talking about, the mass of minor marks and modifications to the built environment, is a mess. It captures categorically a diversity of semi-private performances bound to daily habits and rituals of passing through familiar and unfamiliar spaces and glancing at the world around us. And it is partly the messiness of the mess that matters in this cultural investigation.

What we see on the street is a composite, a laminate as it were: "whose two leaves cannot be separated without destroying them both: the windowpane and the landscape, and why not: Good and Evil, desire and its object: dualities we can conceive but not perceive" (Barthes 5). The pedestrian's experience of modification's mass ornament is one that moves between recognition and misrecognition; visibility and invisibility, but mostly agnosis: an outsider's view of a scene making a scene where there might be none. One other take away from this research is that modifying your environment is fun and contributes to a hyperlocal economy of cultural capital. Viz ESPO's boycentric rules of graffiti:

graffiti is free, impresses the girls, is heroic in our couch potato culture, will provide you with a million stories to tell at parties, and a sure cure for the inner-city blues. If it's not fun, you're doing it wrong or have been doing it too long. So get going, fame awaits the fly among you. ${ }^{4}$

In some way minor marks seem to be the mode of communication that is proper to pedestrian circulation; just as the bumper sticker is a mode of communication proper to automobile transportation.

Minor marks are surface-level phenomena that come into view only through acts of dwelling and passing through. These phenomena produce spectator collectivities bound together loosely by a common perceptive regime: I recognize some of these signs, others are mystical. Some I can barely discern as letters. They mark me as an outsider to an inside joke, or to something bigger, maybe. Driving a car smudges away the weirdness of the world and replaces it with something else. From the familiarity and safety of the car the world outside is more orderly, its rough edges only intimated by broad strokes and red lights. The hyperlocality of mark making reminds me that while I live on

${ }^{4}$ ESPO is Stephen J. Powers, graffiti artist from 1990s. 
the East Side, I don't live at this spot. And even more local marks are not for me. This mass ornament is not meant to be decoded broadly; maybe it doesn't mean anything at all.

These marks, whose authors will generally remain unknown to us, make up a vibrant collage. They are diverse, ephemeral signs that mock, tease, curse, and remember themselves; that locate their authors as much as their spectators. They are marks that talk simply about ordinary practices with the banal flare of execution (Highmore 169). Minor marks are casual marks; deliberate but also not clearly demonstrating commitment to cause, art, or social order. They begin to expand on their boundary when they are expanded on a mass scale (as with Shepherd Fairey's famous Andre the Giant OBEY stickers). The gestural currency of minor marks point to an enduring ethic of modification, a playful appropriation of built environment that is cowed neither by challenge nor prohibition. Perhaps the flattened and anonymous world of the Internet will continue to embolden people to question the right of the edifice to both structural and superficial integrity.

An attunement to the least important and most common of everyday vandalisms draws us closer to a pre-established ethics of publication on the streets. The contingent-ephemerality of minor modifications to the built environment produces layers of history and has the capacity to puncture the bored entitlement of bourgeois space, or maybe not. Maybe it's just fucking around for shits and giggles.

\section{Getting Down}

Street art in its most literal sense is that stuff that happens on the street itself, not the walls. While everything that happens on the walls can also happen on the streets, there is something else that occurs on ground level that you'll never see up on bricks, fences, and barriers: drip-writing (or drip-tagging). Gravity plus a creative desire to express oneself in public are its basic ingredients. I'm not exclusively interested in drip-writing but it certainly is the most unique and particular-to-thestreet of the street art forms for its reliance on that fundamental force of nature. In my ongoing exploration of minor marks and modifications, to the shifting positions of the mobile spectator, it is the modes of attention that emerge as a definitional thread. Street art persists but really comes to life in moments of acute attention where the street is not only visible but memorable.

Where Joe Austin writes about the art of 'getting up' in the context of social capital and New York minority youth, we might imagine this as the art of getting down. All in all it is about getting it out there. One's name. Shepherd Fairey's ubiquitous OBEY stickers stand out as a pre-web example of ubiquity and range. One of the unique things about the graffiti arts is their site specificity. It is unclear if the internet has undercut this. Digital publication and web circulation certainly allow for the mass distribution of images of graffiti but they never really capture the feeling of being there in place ${ }^{5}$.

5 The images published here are part of a series of photographs called "Foot Traffic." Copyleft: Craig Campbell, 2014. 
TranscUlturAl, vol. 6.1 (2014), 16-27.

http://ejournals.library.ualberta.ca/index.php/TC

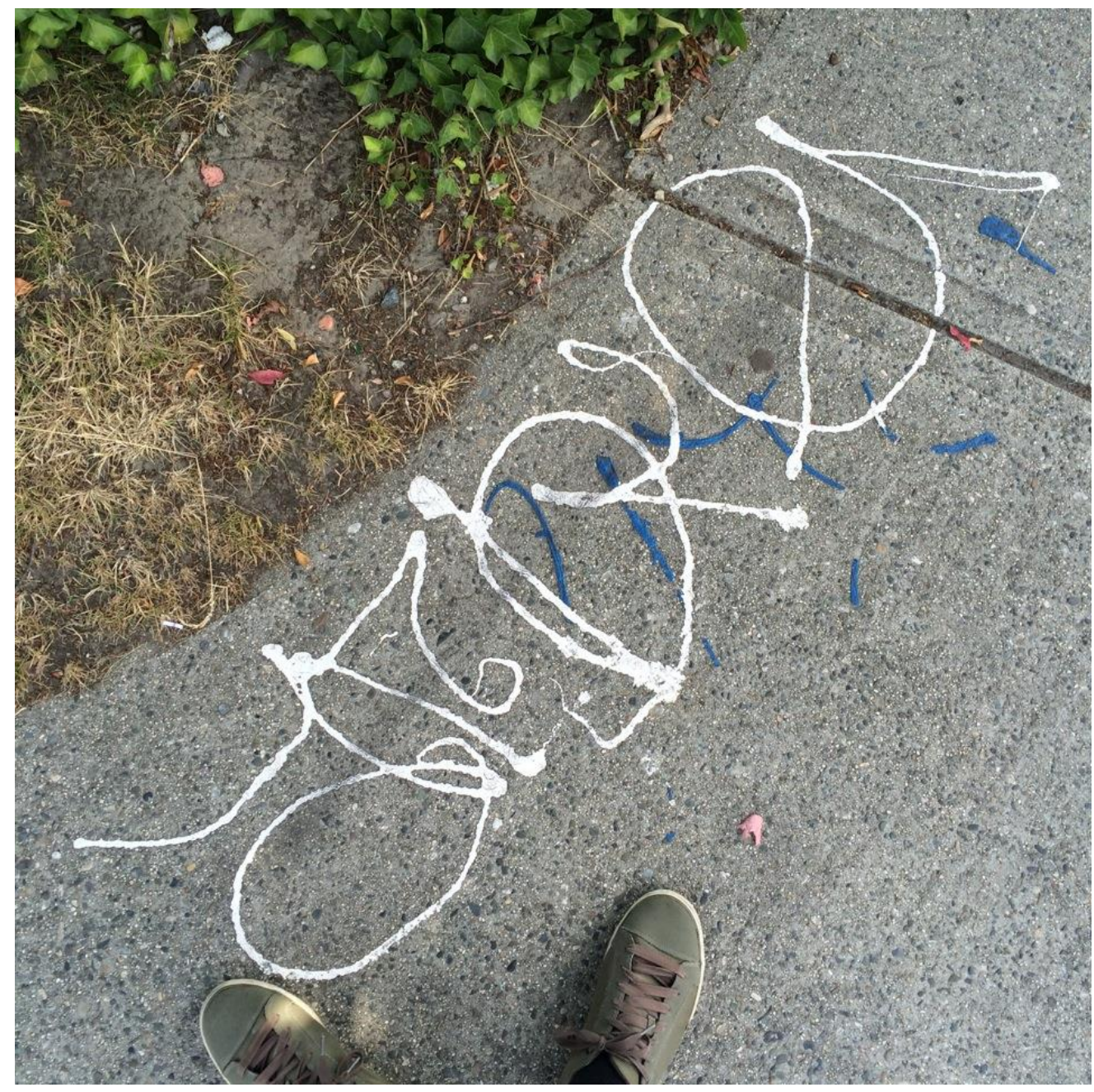


TranscUlturAl, vol. 6.1 (2014), 16-27.

http://ejournals.library.ualberta.ca/index.php/TC

\section{REFERENCES}

Austin, Joe. "More to See than a Canvas in a White Cube: For an Art in the Streets." City 14.1-2 (2010): 33-47.

Barthes, Roland. Camera Lucida: Reflections on Photography. Trans. Richard Howard. 1st American ed. New York: Hill and Wang, 1981.

Baudrillard, Jean. The System of Objects. Trans. James Benedict. Verso, 2005.

Burroughs, William S. The Adding Machine: Selected Essays. Arcade Pub., 1993.

De Certeau, Michel. The Practice of Everyday Life. Trans. Steven Rendall. Berkeley: University of California Press, 1984.

Gordon, Eric. The Urban Spectator: American Concept-Cities from Kodak to Google. 1 edition. Hanover, NH: Dartmouth, 2010.

Highmore, Ben. Everyday Life and Cultural Theory: An Introduction. London; New York: Routledge, 2002.

Kumar, Srini. Sticker Nation: The Big Book of Subversive Stickers. Stk edition. New York, NY: Disinformation Books, 2009a.

—. Sticker Nation 2. Red Wheel Weiser, 2009b.

Powers, Stephen. The Art of Getting over: Graffiti at the Millenium. 1st ed. New York: St. Martin's Press, 1999.

Revelli, M. "Introduction 123." Juxtapoz,2011: 8.

Straw, Will. "Scenes and Sensibilities." Public 22-23 (2001): 245-257.

Sturken, Marita, and Lisa Cartwright. Practices of Looking: an Introduction to Visual Culture. Oxford; New York: Oxford University Press, 2001.

Žižek, Slavoj. The Parallax View. Cambridge, Mass: MIT Press, 2006. 